\title{
A INTEGRAÇAO SOCIAL NA TEORIA SOCIOLÓGICA PARSONIANA
}

\author{
Celso Antonio Favero ${ }^{1}$
}

Resumo: Neste trabalho desenha-se os contornos da teoria parsoniana da integração social, com o objetivo de mostrar como ela continua presente nas abordagens hegemônicas da integração econômica ou da integração dos mercados. Durante os anos 1940-1970, ela tornouse uma espécie de paradigma incontornável para os que pretendiam formular teorias da integração social ou econômica no interior do multilateralismo, que consistia, essencialmente, numa integração social subordinada ao crescimento econômico. Nas décadas seguintes, o modelo foi intensamente bombardeado em virtude, principalmente, de transformar o conflito social numa espécie de anomalia. Com a difusão do neoliberalismo, o modelo parsoniano é novamente recuperado, muitas vezes de formas não explícitas, no contexto de algumas das abordagens sistêmicas de caráter funcionalista e, particularmente, com o objetivo de dar sustentação às teorias da integração dos mercados. No texto a seguir faz-se uma revisão histórico-teórica do pensamento de Parsons, tecendo-se alguns questionamentos. Inicialmente, é apresentada a sua teoria da ação; transita-se para a teoria do sistema; e finalmente apresentase algumas das dimensões consideradas básicas da teoria do sistema, ou seja, suas perspectivas normativa, evolutiva e a da recusa em considerar a desigualdade, a diferença e a exclusão como dimensões inerentes ao próprio sistema capitalista. Aponta-se, ainda, para o crescimento da tendência, atualmente, em retomar a tese hegemônica dos anos 1940-1970, que transforma a integração social em mera decorrência da integração econômica.

\section{Palavras-chave: teoria da integração, ação social, Parsons.}

${ }^{1} \mathrm{PhD}$ em Sociologia pela Université du Québec à Montréal (UQAM), professor adjunto na Universidade Estadual do Oeste do Paraná - UNIOESTE / Campus de Toledo. 


\section{Revista Eletrônica do NDP \\ V.1, n.1, jan./jun.2006}

\section{Introdução}

Este trabalho tem como referência estudos realizados no processo de elaboração de um dos capítulos da tese de doutorado do autor, defendida no final de 1997, e cujo objetivo principal consistia em interpretar os novos modos de pensar e de estruturar o desenvolvimento, naquela encruzilhada histórica que tinha, de um lado, a crise do keynesianismo/fordismo e, de outro, a emergência do neoliberalismo. Naquele contexto considerou-se que, para se fazer uma abordagem adequada dos novos desdobramentos na elaboração de modelos de desenvolvimento, era necessário retomar, como foco principal, o estudo do conceito de integração social. Foi por essa via que se encontrou Parsons. Mas, pode-se perguntar, por que Parsons? A resposta parece simples: Talcott Parsons é reconhecido como "o sociólogo da integração" (Bourricaud, 1977) em virtude da importância que ele atribui a esta noção na sua elaboração teórica. Mas, há pelos menos duas outras razões que nos levam a tomar a obra parsoniana como ponto de partida para interpretar a sociologia moderna da integração.

Primeiro, como sublinha Habermas (1987, p.217), “ninguém entre os contemporâneos desenvolveu uma teoria da sociedade tão completa como a de Parsons". Habermas insiste ainda afirmando que ninguém foi tão longe quanto Parsons no sentido de tentar conciliar as teorias da ação com as do sistema. Parsons elaborou uma das sínteses mais completas da sociologia da modernidade, que é a síntese funcionalista. Trata-se de uma elaboração extremamente complexa, através da qual o autor articula dois campos teóricos, o da ação social ao do sistema social, de modo que o sistema social emerge como um todo, universal, integrado, que opera sobre os indivíduos e determina as suas próprias ações, constituindo-se, portanto, como o verdadeiro sujeito social. Esse sistema é, por um lado, uma estrutura integrada e, por outro, um sistema em evolução, de modo que as próprias formas de integração mudam no processo. 


\section{Revista Eletrônica do NDP \\ V.1, n.1, jan./jun.2006}

Segundo, nos Estados Unidos, no período entre as duas guerras mundiais, ninguém esteve mais no centro dos grandes debates na sociologia que Parsons (Rocher, 1972; Alexander, 1987). Em seguida, ou após a Segunda Guerra, o modelo por ele elaborado tornouse paradigmático e, pode-se dizer, quase o único modo válido de interpretar a sociedade, pelo menos nos Estados Unidos. Além disso, na medida em que este país emergia como a potência ocidental hegemônica, Parsons tornou-se um dos seus produtos de exportação, de modo que a sua influência estendeu-se entre as Américas e por toda a Europa. É verdade que, mais recentemente, ou a partir da década de 1960, o modelo entrou em crise. No entanto, hoje, novamente, ele está presente em inúmeras abordagens nas ciências sociais e, também, econômicas, o que nos convence da necessidade de, pelo menos, conhecê-lo.

Considerando isso, este trabalho, cujo objetivo maior é resgatar os principais elementos da teoria parsoniana da integração social, foi estruturado em três momentos, que seguem, de certo modo, o próprio caminho da elaboração feita por Parsons. Assim, no primeiro momento, tem-se como intenção apresentar uma breve síntese da teoria da ação social. Em seguida, sempre centrada no conceito de integração social, e também de modo bastante sintético, é reconstruída a teoria parsoniana do sistema social. Finalmente, é repassada a obra parsoniana com o objetivo de propor algumas críticas ao seu sistema da integração social. Nessa última parte, os conceitos básicos são os de igualdade/desigualdade, diferenciação e exclusão social.

\section{A teoria da Ação Social}

Em Parsons, a tensão entre a teoria da ação e a teoria do sistema desenvolve-se gradualmente. É primeiramente no livro The Structure of Social Action: a study in social 


\section{Revista Eletrônica do NDP \\ V.1, n.1, jan./jun.2006}

theory with special reference to a group of recent European writers (1968) que ele desenvolve as idéias de base de uma teoria da ação. Mas é precisamente em Economy and society: a study in the integration of economic and social theory (1964), e em Theories of society (1961), que ele desenvolve a teoria do sistema. Finalmente, é no livro Le système des sociétés modernes (1973) que Parsons elabora de maneira mais consistente a teoria da mudança social.

Nessas obras, do mesmo modo que em Weber, a teoria da ação se concentra na ação do ponto de vista de um ator, enquanto que a teoria do sistema aborda as conseqüências de uma atividade para um sistema de atividades. Nessa tensão que opõe as duas teorias, Parsons afirmará até o fim o primado metodológico da teoria da ação, apesar de que, “[...] se fizermos falar a própria construção da teoria, tem-se a impressão de que Parsons deu outra resposta" (Habermas, 1987, p.219). Mas, de todo modo, a teoria do sistema é, para Parsons, um prolongamento da teoria da ação. Esta é a dimensão sistemática sempre perseguida por Parsons.

Parsons concebe a sociedade global ou o sistema humano da ação como a integração de indivíduos e coletividades, por intermédio de seus atos, a um sistema imperativo de valores ou de normas (Parsons, 1968). De acordo com Parsons, e como sustentava Weber, o objeto da sociologia é a ação social operada pelos indivíduos e, subseqüentemente, por coletividades. Mas, enquanto Weber definia esta ação por meio do sentido dado pelo indivíduo que a realizava, Parsons a concebe como "[...] constituída pelas estruturas e processos através dos quais os seres humanos emitem intenções significativas e, com maior ou menor sucesso, as encarnam em situações concretas” (Parsons, 1968, p.718), que se traduzem em instituições.

O sistema de ação concebido por Parsons (ver figura 1) comporta quatro subsistemas, com as suas respectivas funções primárias: o social com a função de integração, o cultural com a função de conservação dos modelos culturais, a personalidade (a política) com a função 


\section{Revista Eletrônica do NDP \\ V.1, n.1, jan./jun.2006}

de realizar fins coletivos e, enfim, o que ele denomina o organismo de comportamento (a economia), com a função primária da adaptação (Parsons, 1973, p.6).

Dentre esses subsistemas, o de integração é o mais importante do ponto de vista da sociologia, de modo que os demais constituem o ambiente no qual ele se insere. No entanto, o subsistema cultural é o mais vasto (ele faz referência à universalidade), enquanto o subsistema social refere-se à institucionalização e, particularmente, a institucionalização normativa de parcelas do subsistema cultural ou do sistema de valores. A sociedade é também um sistema de pertencimento (das personalidades e dos comportamentos) e da busca de uma crescente gama de possibilidades de institucionalização e adaptação. Do mesmo modo que Spencer, Parsons atribui grande importância à economia nos processos de adaptação.

Figura 1 - O Sistema da Ação Social

\begin{tabular}{|l|l|}
\hline Subsistema & Funções primárias \\
\hline Social & Integração \\
\hline Cultural & Conservação dos modelos culturais \\
\hline Da personalidade & Realização dos fins coletivos \\
\hline Organismo de comportamento & Adaptação \\
\hline
\end{tabular}

Fonte: figura extraída do livro "Le système des sociétés modernes", da Edição francesa publicada pela Dunod, 1973.

Já que o subsistema social ou o sistema de integração repousa inicialmente sobre as interações dos indivíduos com base em suas ações, o sistema não pode ser definido, em princípio, como uma totalidade fechada e auto-suficiente que constrange os indivíduos pela imposição de significados, valores e normas transcendentes. No entanto, se este subsistema é, por um lado, o resultado da trama do eterno arbítrio dos indivíduos, por outro lado, estes indivíduos estão inseridos em um sistema de valores (cultural); eles interiorizam os sistemas de normas identificando-se a eles. Ou, como sublinha Habermas, enquanto as ações se desenvolvem com a consciência dos atores, o sistema penetra silenciosamente as suas 


\section{Revista Eletrônica do NDP \\ V.1, n.1, jan./jun.2006}

orientações. Desse modo, "o sistema cultural é constituído pela ação dos indivíduos" (Habermas, 1987, p.220).

No sistema cultural, cada indivíduo é, ao mesmo tempo, um ator (com seus objetivos, idéias, atitudes, etc.) e um objeto de orientação ao mesmo tempo para os outros atores e para ele mesmo (Parsons, 1973). Apesar disso, insiste Parsons, este indivíduo não pode contribuir para a criação ou a destruição deste sistema senão de forma marginal. O primado do sistema de ação sobre os sujeitos, e mesmo sobre a comunidade societal, torna-se então evidente. A sociedade, ou o sistema social emerge, assim, como uma sociedade sem verdadeiros atores.

\section{A teoria do Sistema Social}

\section{O Sistema Social - noções básicas}

Parsons foi o sociólogo que deu à noção de sociedade a sua forma mais elaborada. Ela repousa "[...] sobre a dupla idéia do triunfo da razão na sociedade moderna e da funcionalidade como critério do bem" (Touraine, 1992, p.406). Com Parsons, mais do que nunca, a noção de sociedade foi concebida como um princípio unificador e, nesse sentido, como o "[...] princípio do bem, enquanto o mal era definido como aquilo que é contrário à integração social” (Touraine, 1992, p.171).

De acordo com Parsons, o sistema de integração, como desdobramento do sistema da ação, compreende quatro subsistemas com suas respectivas funções primárias. Esses subsistemas são o social, o cultural, o político e o econômico, cujas funções primárias são, respectivamente, a integração, a conservação dos modelos culturais, a realização de fins coletivos e a adaptação. O cerne do sistema de integração é a comunidade societal cuja “[...] função mais geral é, provavelmente, a de articular um sistema de normas com uma organização coletiva que possui unidade e coesão..." (Parsons, 1973, p.12). O autor sublinha em seguida que “[...] a função principal do subsistema de integração é de definir as obrigações 


\section{Revista Eletrônica do NDP \\ V.1, n.1, jan./jun.2006}

de lealdade para com a comunidade societal, tanto as que emergem do pertencimento global à sociedade quanto as que se referem às diferentes categorias de estatutos e de papéis diferenciados no interior da sociedade" (Parsons, 1973, p.13).

A comunidade societal repousa, portanto, sobre normas legais, universalistas e generalizadas e, assim, no pertencimento social, expresso através de suas formas civis, políticas e sociais. Essa comunidade emerge, portanto, como um sistema ou como um espaço de integração social fundado em instituições normativas e que se materializa, na modernidade, através das sociedades nacionais.

Quadro 1 - O Sistema Social segundo Parsons

\begin{tabular}{|l|l|l|l|}
\hline Subsistemas & $\begin{array}{l}\text { Componentes } \\
\text { estruturais }\end{array}$ & $\begin{array}{c}\text { Aspectos do Processo de } \\
\text { desenvolvimento }\end{array}$ & \multicolumn{1}{|c|}{$\begin{array}{c}\text { Funçães } \\
\text { primárias }\end{array}$} \\
\hline Social & Normas & Inclusão & Integração \\
\hline Cultural & Valores & Generalização dos valores & $\begin{array}{l}\text { Conservação dos } \\
\text { modelos culturais }\end{array}$ \\
\hline Político & Coletividades & Diferenciação & $\begin{array}{l}\text { Realização de } \\
\text { fins coletivos }\end{array}$ \\
\hline Econômico & Papéis & Melhoramento adaptativo & Adaptação \\
\hline
\end{tabular}

Fonte: Elaborado a partir do esquema proposto por Parsons (1973).

O sistema de integração, cuja essência é constituída pela comunidade societal, se insere em um determinado ambiente. Neste ambiente, o subsistema cultural, com a função de manutenção dos modelos, é o mais vasto e representa a base sobre a qual se definem as normas, enquanto o subsistema econômico, com a função de adaptação, ocupa o primeiro lugar no sentido condicional ou enquanto sistema de adaptação. Este último (econômico) é o subsistema mais rico em energia e o mais visível para os atores sociais, em virtude de que ele se refere a questões de ordem prática. Parsons retoma assim, novamente, a concepção spenceriana do papel das necessidades na sociedade. Finalmente, o subsistema político, que visa à realização de fins coletivos, conduz à diferenciação no interior da comunidade societal 


\section{Revista Eletrônica do NDP}

V.1, n.1, jan./jun.2006

e, ao mesmo tempo, à formação de coletividades, com vínculos de pertencimento mais rígidos.

\section{O Sistema Social é um sistema normativo}

No sistema parsoniano da ação social e do sistema social, um lugar central é atribuído ao conceito de normatividade ou de institucionalização. De acordo com Parsons, o cerne de uma sociedade é a ordem normativa, que organiza coletivamente a vida de uma determinada população (Parsons, 1973). Essas normas ou instituições não são fundadas no vazio; elas fazem referência ao subsistema cultural do sistema da ação. Desse modo, a sociedade é constituída, ao mesmo tempo, por um sistema normativo e por estatutos, por direitos e obrigações, podendo variar de um subgrupo da comunidade para outro, que são ligados ao fato de serem membros.

Esta ordem normativa ou institucional constitui o índice de medida da estabilidade relativa e do grau de desenvolvimento de uma determinada sociedade e se torna mais visível no domínio da regulação da produção ou da economia. Segundo Parsons, nas sociedades modernas, o aspecto normativo está presente de modo mais evidente na regulação das relações de trabalho ou na produção (Parsons, 1973). Além disso, na economia, o dinheiro e o mercado estão entre os conjuntos institucionais mais importantes (Idem, 1973). Ou seja, é no campo econômico e normativo que Parsons irá mais longe no desenvolvimento da noção de integração social, que é concebida como a conexão de ações no interior de um contexto garantido pelas normas. Por fim, o que Parsons ressalta na sua concepção da economia é que a sociedade é essencialmente uma sociedade industrial.

\section{O Sistema Social é um sistema em evolução}




\section{Revista Eletrônica do NDP \\ V.1, n.1, jan./jun.2006}

A sociologia parsoniana não estaria completa se esquecermos a outra dimensão da sociedade, a da mudança evolutiva ou da complexificação. Esta dimensão da sociedade é primeiramente distinta daquela que Parsons denomina como a da mudança estrutural (Rocher, 1972, p. 98). A mudança de estruturas se caracteriza por transformações bastante importantes na organização e no funcionamento de uma sociedade. Nesse caso, trata-se da passagem, por exemplo, da sociedade tradicional para a sociedade industrial ou moderna (Parsons, 1973).

Para fazer a análise da mudança social, Parsons utiliza o paradigma da mudança evolutiva, atribuindo-lhe uma interpretação bastante próxima daquela dada por Spencer. De acordo com Parsons, o processo de complexificação social, caracterizado pela interação social, se concentra no nível simbólico ou sobre a linguagem (o subsistema cultural). Quatro mecanismos ou processos marcam esta evolução histórica: a diferenciação, o melhoramento adaptativo, a inclusão e a generalização dos valores.

Na evolução histórica, o processo de diferenciação se acentua na medida em que as comunidades societais se tornam mais complexas e mais abertas. Ou seja, a complexificação social (expressão da evolução) é, por um lado, a base da diferenciação dos sistemas parciais (comunidades societais), que são relativamente autônomos uns em relação aos outros, e mediados por um sistema mais geral, que é o sistema de valores. Passando por diferentes mediações, esses sistemas mudam e se imbricam. Por outro lado, entre os processos de mudança, o crescimento da capacidade de melhoramento adaptativo aparece como a mais importante na perspectiva evolutiva. De acordo com Parsons: “o melhoramento adaptativo é o processo que coloca à disposição das unidades sociais um campo mais vasto de recursos, de modo que o seu funcionamento possa se liberar de determinados limites que conheceram os seus predecessores" (1973 p.29). O melhoramento adaptativo é essencialmente da ordem da economia. $^{2}$

\footnotetext{
${ }^{2}$ É importante perceber como esta idéia é retomada atualmente com entusiasmo por estudiosos de diversas correntes das ciências sociais e, sobretudo, das ciências econômicas (Soltwedel, 1993; Rosenthal, 1994).
} 


\section{Revista Eletrônica do NDP \\ V.1, n.1, jan./jun.2006}

A evolução social, ou o processo de diferenciação social introduz nos sistemas sociais novos problemas relativos à integração. Por exemplo, o alargamento da segmentação social (do campo da especialização) exige a liberação dos vínculos que existiam entre o sistema e as novas especializações e a criação de novos patamares de integração e de coordenação sistêmica. A integração social se faz, assim, através da inclusão social.

Deste ponto de vista, sublinha Parsons, os processos de diferenciação e de melhoramento adaptativo podem exigir a inclusão, “[...] com o estatuto de membro de plenos direitos no seio da comunidade, de grupos até então excluídos e que adquiriram capacidades legítimas de contribuir para o funcionamento do sistema" (Parsons, 1964, p.538). Eles permitem, também, uma integração parcial de determinados indivíduos ou grupos sociais e, inclusive, a recusa de toda integração. A integração cria, assim, estratificações sociais com diferentes estatutos. Este modo de ver o processo evolutivo permite também a possibilidade de pensar a exclusão social, apesar dela ser tratada como uma coisa do passado. O autor ilustra o fenômeno da inclusão social por meio do seguinte exemplo: “[...] nos sistemas divididos em classes inferiores e superiores, e no interior dos quais a classe dominante monopoliza o estatuto de membro real, esta trata a classe dominada, na medida em que esta é apenas aceita, como uma classe composta de cidadãos de segunda classe" (Parsons, 1964, p.538).

Nesse sentido, a inclusão pode ser o resultado de um debate ou de um enfrentamento entre os dominantes (o centro) e os dominados (os marginais), mas, sobretudo, uma exigência do próprio sistema (que é o verdadeiro ator social). Os que estão no centro podem oferecer um reconhecimento mais ou menos limitado aos marginais, ou mesmo recusar indefinidamente este reconhecimento. Esta perspectiva parsoniana poderia permitir ver a questão da integração social pelo caminho, senão do conflito, pelo menos da tensão. No 


\section{Revista Eletrônica do NDP \\ V.1, n.1, jan./jun.2006}

entanto, é o próprio Parsons que sublinha, como já foi visto, que a inclusão social é uma exigência do sistema, mais do que o resultado de um enfrentamento ou de um conflito.

Finalmente, nessa perspectiva evolutiva da mudança social, é introduzida a idéia de que, em todos os tempos, algumas sociedades se transformaram em sociedades "matrizes" (Parsons, 1973, p.31). Na modernidade, por exemplo, a primeira grande matriz foi à Inglaterra, a partir do século XVII, que foi substituída no curso do século XX pelos Estados Unidos. Mas, enquanto na Europa as sociedades modernas se constituíram com base na etnia (raça) e na nação (território), na América do Norte, ela se formou com base no associacionismo e na cidadania (Parsons, 1973, p.97). Nesse sentido, afirma Parsons, "[...] a sociedade americana foi mais longe que todas as grandes sociedades na dissociação das antigas desigualdades atribuídas e na institucionalização de um modelo social fortemente igualitário... Ela institucionalizou um campo de liberdades mais largo que qualquer sociedade anterior" (Idem, p.122). É por esse meio que Parsons cruza, de maneira rica e específica, o campo da sociabilidade primária ou tradicional (a comunidade local) com o da sociedade moderna (a comunidade nacional).

\section{A desigualdade, a diferenciação e a exclusão social}

A sociedade moderna é, em princípio, uma sociedade constituída de iguais. Segundo Parsons: “[...] uma comunidade societal, composta de iguais na base, parece ser o ponto de chegada do longo processo que negou a legitimidade das bases dos pertencimentos atribuídos, mais antigos e mais particularistas, que são a religião (numa sociedade pluralista), a origem étnica, a região ou a localidade, e a posição hereditária na estratificação social..." (Parsons, 1973, p.126). O exemplo mais perfeito deste tipo de sociedade (igualitária) seria, do ponto de vista de Parsons, a sociedade americana. 


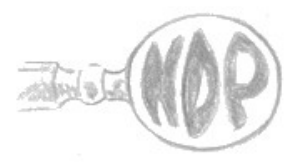

\section{Revista Eletrônica do NDP \\ V.1, n.1, jan./jun.2006}

Neste contexto, como se coloca para Parsons o problema da desigualdade social que atinge inclusive, e ainda hoje, a sociedade americana? Primeiro, de acordo com o autor, a desigualdade social não significa uma forma de privação absoluta; ela é, sobretudo, uma privação relativa ou uma exclusão da plena participação na comunidade societal. Segundo, a igualdade não é a mesma coisa que a diferenciação. De acordo com o autor, por trás das novas lutas sociais, por exemplo, por trás das lutas anti-racistas nos Estados Unidos, encontramos de maneira bastante clara a manifestação de um desejo de inclusão. Este desejo estaria também fundado num “[...] acordo praticamente unânime sobre a necessidade de ultrapassar a linha da pobreza pelos que estão além dela" (Parsons, 1973, p.123).

A igualdade a que Parsons se refere é, portanto, a igualdade no nível dos valores e das normas, enquanto a diferenciação se refere particularmente aos aspectos econômicos e políticos. Segundo Parsons, do mesmo modo que para Spencer, a sociedade é essencialmente assimétrica. No entanto, na perspectiva evolucionista proposta por Parsons, esta sociedade é também fundada no desejo de inclusão, e não em termos de confronto ou de conflito. Decorre disso, também, que a exclusão social é relativa e, fundamentalmente, uma exclusão de natureza econômica (isso significa que ela repousa num déficit). Ela não constitui, portanto, uma ruptura maior no nível do pertencimento social. Por outro lado, ainda nessa perspectiva evolucionista de Parsons, as tendências presentes nos processos históricos encaminham para o desaparecimento de toda exclusão e para uma nova integração social, cada vez mais universal e completa, realizada pela inclusão e pela adaptação.

Ou seja, por trás dessa concepção proposta por Parsons, encontramos sempre o sistema da ação social, a partir do qual a sociedade se explica. Nessa perspectiva, a adaptação a um determinado sistema, que é um sistema de valores, é o instrumento mais importante para o avanço e a universalização da integração. Como sublinha freqüentemente Parsons (1973), esta 


\section{Revista Eletrônica do NDP \\ V.1, n.1, jan./jun.2006}

integração é estabelecida com base em conexões de ações num contexto garantido por normas e, quanto mais a sociedade evolui, mais eficaz torna-se o sistema de adaptação.

O que convém reter da teoria proposta por Parsons é, primeiramente, a idéia de universalidade sobre a qual se funda a concepção de sociedade. A sociedade é, assim, uma sociedade integrada na base, apesar de que, no nível da participação, (da comunidade societal), encontramos freqüentemente a desigualdade. Em segundo lugar, com base na idéia de evolução, Parsons nos confronta com uma sociedade-projeto. Ou, como sublinham Olson e Groom (1991, p.151) ao interpretarem a influência do modelo parsoniano nas ciências políticas após a Segunda Guerra, em Parsons, o sistema social é sempre, e ao mesmo tempo, uma situação (estática) e um processo (evolução). Nesse sentido, mesmo a desigualdade social e econômica tende a diminuir e a desaparecer. Esta evolução se faz pela via da inclusão em instituições e pela adaptação. O que é importante é, então, a idéia segundo a qual a sociedade caminha na direção da sua própria realização, ou em direção da integração universal. Se ela ainda não atingiu este objetivo, ela o fará necessariamente um dia. A desigualdade é, nesse ponto de vista, não natural, mas artificial.

\section{Considerações finais ou a crise do modelo parsoniano}

Nas comunidades societais (ou no interior das sociedades nacionais), ao longo da história, a questão social foi colocada de diversas maneiras. Assim, no período que se segue a Segunda Grande Guerra, que foi fundado em "um novo consenso universal” (Olson e Groom, 1991), o modelo parsoniano tornou-se hegemônico e foi amplamente aplicado na estruturação das políticas. Parafraseando o próprio Parsons, durante este período, como em geral na história do capitalismo, a dimensão social esteve subordinada à da economia. Em decorrência disso, a dimensão política, centrada na figura do Estado, passou a operar como uma mediação entre a economia e a sociedade, subordinando a última à primeira. 


\section{Revista Eletrônica do NDP \\ V.1, n.1, jan./jun.2006}

Durante este período, nas comunidades societais, e mais particularmente nas comunidades societais ocidentais, a integração social era da competência dos Estados nacionais, que foram assim convertidos em Estados sociais. Ou, como sublinha Robert Castel (1995, p.268), podemos interpretar o crescimento do Estado social como a introdução de um terceiro elemento entre os partidários da moralização do povo (o liberal funcionalismo) e os que defendiam a luta de classes (marxismo). Com a criação desta mediação, o problema da dissolução dos conflitos de interesses (por meio da violência institucionalizada) foi substituído pela negociação de compromissos. Desse modo, segundo o autor, este novo Estado, ou o estado social, supõe o antagonismo de classes, ao mesmo tempo em que o contorna. É esta espécie de fuga do conflito que se torna o âmago das estratégias políticas das últimas décadas, particularmente nos países industrializados.

Foi nesse contexto que os Estados, aspirando a coesão social, criaram instituições e sistemas de seguridade social mais ou menos complexos, ao mesmo tempo em que se erigiram como Estados-Providência buscando “[...] livrar os cidadãos dos riscos mais freqüentes de uma sociedade industrial, particularmente nos campos do trabalho, da doença, do envelhecimento, do desemprego...” (Merrien, 1994, p.9). Esta integração se fazia, seja pela inserção ou inclusão social, seja através do alargamento do espaço da integração.

No entanto, o modelo é uma coisa e a realidade é outra. Ou, como sustenta Parsons, a comunidade societal não reflete de modo algum a realidade da sociedade. Ela é mais que tudo um ideal. É assim que, na prática histórica, as estruturas sociais e as abordagens mais diversificadas caracterizaram a questão social. Globalmente, durante o período do pós Guerra, poderíamos dizer que os países industrializados desenvolveram sistemas quase universais de seguridade social, fundados no modelo preconizado por Beveridge. Nos países periféricos, de modo geral, foram criados sistemas parciais e fragmentados, apoiados, por exemplo, como na América Latina, no modelo proposto por Bismarck (Stahl, 1994). No entanto, mesmo nesses 


\section{Revista Eletrônica do NDP \\ V.1, n.1, jan./jun.2006}

países, e o caso do Brasil é ilustrativo, a integração universal foi vivida pela maioria da população como esperança, no que resgata a perspectiva parsoniana da evolução.

Sintetizando, o modelo parsoniano, que foi presumido como paradigmático após a Segunda Guerra na própria estruturação da idéia de sociedade e na refundação dos Estados nacionais solicitada pelo novo consenso universal, encontra seus limites no interior do próprio sistema, na medida em que, fundado na perspectiva funcionalista, não permite apanhar as contradições e, assim, os conflitos sociais, que são inerentes à própria sociedade capitalista. Mais que isso, enquanto modelo ou uma espécie de tipo ideal, claudica quando confrontado com a realidade da materialidade das formações sociais. Parsons propõe uma solução para esse segundo problema, ao reinserir a dimensão evolutiva no tratamento do sistema social, de modo que ele concebe a igualdade social não como um dado, mas como uma meta. No entanto, como já foi ressaltado, na estruturação do discurso hegemônico sobre a sociedade, ou por meio da representação da sociedade, o "vir a ser" (meta) foi transformado numa espécie de "sendo". Ou, em outros termos, o modelo parsoniano serviu, e serve ainda, como instrumento dos Estados e das elites sociais para a legitimação da desigualdade e da exclusão social.

\section{Referências}

ALEXANDER, Jeffrey C. Twenty lectures sociological theory since World War II. New York : Columbia University Press, 1987.

BOURRICAUD, François. L'individualismo institutionnel. Essai sur la sociologie de

Talcott Parsons. Paris : PAF, 1977.

CASTEL, Robert. Les métamorphoses de la question sociale. Une chronique du salariat. Paris : Fayard, 1995. 


\section{Revista Eletrônica do NDP \\ V.1, n.1, jan./jun.2006}

HABERMAS, Jürgen. Théorie de l'agir communicationnel. Tome 2: Critique de la raison fonctionnaliste. Paris : Fayard, 1987.

MERRIEN, François-Xavier. Face à la pauvreté. Paris : Les Editions de l'Atélier/Editions Ouvrières, 1994.

OLSON, William C. e GROOM, A. J. R. International relations then \& now. Origins and Trends in Interpretation. London : Harper Collins Academic, 1991.

PARSONS, Talcott e SMELSER, Neil J. Economy and society. A study in the integrations of economic and social theory. New Jersey : Free Press of Glencoe, 1964.

PARSONS, Talcott. Le système des sociétés modernes. Paris : Dunod, 1973.

PARSONS, Talcott. The structure of social actions: A study in social theory with special reference to a group of recent european writers. New York : Free Press, 1968.

PARSONS, Talcott. Theories of society: Fundations of modern sociological theory. New York : Free Press of Glencoe, 1961.

ROCHER, Guy. Talcott. Parsons et la sociologie américaine. Paris : Presses Universitaires de France. 1972.

ROSENTHAL, Gert. America Latina y el Caribe frente a la economia mundial. Revista de la CEPAL , n. 53, 1994, p. 7-21.

SOLTWEDEL, Rüdiger. Ajustement Structurel, croissance économique et emploi. Révue de l'OCDE Migrations Internationales: le tournant. 1993, p. 61-73.

STHAL, Karin. Politica social en America Latina. La privatización de la crise. Nueva Sociedad, n. 131, Mayo-Junio 1994, p. 48-72.

TOURAINE, Alain. La critique de la modernité. Paris : Fayard, 1992. 